\title{
Influência da certificação florestal no cumprimento da legislação ambiental e trabalhista na região amazônica
}

\author{
Vanessa Maria BASSOํㅗ , Laércio Antônio Gonçalves JACOVINE², Ricardo Ribeiro ALVES³ , Sophia Lorena \\ Pinto VIEIRA ${ }^{4}$.
}

\begin{abstract}
RESUMO
Nas últimas décadas tem surgido uma maior preocupação ambiental advinda das mudanças climáticas e dos desmatamentos contínuos das florestas tropicais. Para conciliar a exploração e a conservação das florestas surgiram alguns mecanismos, entre eles a certificação florestal. No Brasil, ela está presente há mais de uma década, através do FSC (Forest Stewardship Council), uma ONG (Organização Não-Governamental) que estabeleceu um padrão para a certificação do manejo florestal. Este padrão possui nove princípios e o primeiro deles trata da "Obediência às Leis e Princípios do FSC", exigindo o cumprimento e respeito de todas as leis aplicáveis ao país onde opera e obedecer a todos os seus Princípios e Critérios. Neste contexto, este trabalho teve por objetivo verificar a influência da certificação florestal no cumprimento da legislação nas unidades de manejo de florestas nativas. Buscaram-se os dados nos relatórios públicos das unidades de manejo certificadas até 2007. A avaliação foi realizada por meio da identificação e análise das principais não-conformidades, com relação ao primeiro princípio. Verificou-se que os principais problemas estavam relacionados à legislação ambiental e trabalhista. As não-conformidades da legislaçáo trabalhista foram em sua maioria referentes aos problemas com trabalhadores terceirizados e a legislação ambiental referentes às áreas de preservação permanente e falta de autorizaçôes de órgãos ambientais. Caso sejam tomadas açôes para resolvê-las, pode-se concluir que a certificação florestal pode contribuir para o atendimento da legislação nas unidades de manejo de florestas nativas.
\end{abstract}

PALAVRAS-CHAVE: FSC, legislação ambiental, legislação trabalhista.

\section{Influence of the forest certification in the compliance of the environmental and labor legislation in the Amazonia Region}

\begin{abstract}
In the last decades environmental concerns have been arising as a result of the climate changes and the ongoing deforestation in tropical regions. To conciliate the exploration and conservation of the forests some mechanisms have, among them the forest certification. In Brazil, it has been presented more than a decade, through the FSC (Forest Stewardship Council), an NGO (Non-governmental organization) which established standard guidelines for forest management certification. Such guidelines have nine principles and the first one deal with "Compliance with laws and FSC Principles", demanding the compliance and respect of all applicable laws of the country where it operates and comply with all their Principles and Criteria. In this context, this study aimed to verify the influence of forest certification in the legislation compliance in the units of management of native forest. Data was collected from public reports of the certificated management units until 2007. The evaluation was made up through the identification and analyses of the main non-conformance, related to the first principle. It was found that the main problems were related to the environmental and labor legislation. The labor legislation non-conformances were mostly related to the problems with the outsourced workers and environmental legislation relating to permanent preservation areas and lack of permit from environmental agencies.
\end{abstract}

KEYWORDS: FSC, environmental legislation, labor legislation.

\footnotetext{
1 UFV. nessabasso@yahoo.com.br

2 UFV. jacovine@ufv.br

${ }_{3}^{3}$ UFV. ricardo.alves@ufv.br

${ }^{4}$ UFV. sophiavieira@hotmail.com
} 


\section{INTRODUÇÃO}

O Brasil é um país florestal no nome e na essência. Segundo a Avaliação dos Recursos Florestais Globais (FRA 2005), "a cobertura florestal do Brasil corresponde a 477,7 milhóes de hectares, dos quais, 89\% estão na Amazônia, ou seja, 426,5 milhôes ha. Inventários realizados em 21 sítios diferentes mostram que o volume médio das florestas naturais na Amazônia é $262 \pm 54 \mathrm{~m}^{3} / \mathrm{h}$ a, dos quais $10 \%$ são considerados comerciais. Isto é um estoque enorme, mas atualmente contribui pouco para o desenvolvimento da Amazônia”. E o crescente desmatamento da regiāo tem alarmado a sociedade e entidades não governamentais provocando diversas reaçóes de protesto por todo o mundo. Desta forma, as pressóes sobre os produtos oriundos de florestas contribuíram para o surgimento de um instrumento que garantisse que os mesmos não fossem ilegais, ou seja, originados de desmatamentos não autorizados.

Uma das estratégias implementadas para alcançar esse objetivo foi o estabelecimento de programas para certificação voluntária do "Bom Manejo Florestal” - o manejo florestal ambientalmente adequado, socialmente benéfico e economicamente viável (Nardelli \& Griffith, 2003). A certificação se apresentou como uma idéia inovadora, pois é um sistema concebido para identificar e rotular unidades florestais e seus respectivos produtos florestais. Sendo assim, em 1993, surgiu o sistema de certificação florestal FSC (Forest Stewardship Council). Desde então, diversas outras organizaçóes ligadas à certificação têm surgido, como a ABNT/CERFLOR no Brasil (Alves et al. 2009). Buscando maior legitimidade mundial a ABNT/CERFLOR obteve em 2005 o reconhecimento do PEFC (Programme for the Endorsement of Forest Certification Schemes), um programa de certificação europeu independente, que atualmente obtém a maior área florestal certificada no mundo, cerca de 220 milhôes de hectares.

Em termos de área no Brasil, o FSC possui 4.720.645 hectares de florestas certificadas, sendo que 2.918.400 hectares estão na região Amazônica (FSC, 2010). Já a ABNT/ CERFLOR possui 1.170.136 hectares de florestas certificadas, mas nenhum na regiāo Amazônica (INMETRO, 2010). Ao buscar uma certificação, as empresas estão lançando mão de um instrumento institucionalizado de diferenciação, com o objetivo de informar e garantir ao consumidor e às demais partes interessadas que determinados padróes de desempenho de seu manejo florestal estão sendo atingidos e monitorados (Nardelli e Griffith 2003). Segundo dados de Alves et al. (2009), a certificação no Brasil tem aumentado, principalmente na região Amazônica que obteve um ganho em sua área de mais de oito vezes entre os anos de 2003 a 2009.

Avaliar a contribuição da certificação florestal nos aspectos econômicos, sociais e ambientais torna-se importante para se conhecer a efetividade deste instrumento. A utilização deste instrumento pode influenciar o emprego do "Bom Manejo Florestal” e, com isso, ampliar as áreas de florestas nativas certificadas, principalmente na Regiāo Amazônica. Entre os princípios do padrão FSC o primeiro trata da "Obediência às leis e aos princípios do FSC". Neste sentido, é importante verificar a real influência desse sistema de certificação para o cumprimento da legislação florestal, ambiental e social, pois, se por um lado o Brasil possui uma das legislaçóes mais avançadas do mundo, por outro possui uma cultura arraigada de descumprimento de leis. Neste contexto, o presente trabalho teve como objetivo avaliar a influência da certificação florestal no cumprimento da legislação ambiental e trabalhista, nas unidades de manejo de florestas nativas na regiâo amazônica.

\section{MATERIAL E MÉTODOS}

O presente trabalho foi desenvolvido a partir de metodologias da pesquisa social, sendo esta caracterizada como uma pesquisa descritiva. Segundo Gil (2008), "as pesquisas deste tipo têm como objetivo primordial a descrição de características de determinada população ou fenômeno ou estabelecimento de relações entre variáveis. Algumas pesquisas descritivas vão além da simples identificação da existência de relaçóes entre variáveis, pretendendo determinar a natureza dessa relação." Desta forma, o trabalho procurou estabelecer a relação entre a adesão ao processo de certificação florestal e o cumprimento de algumas legislaçóes, em específico, a ambiental e trabalhista, verificando assim, a influência da variável certificação sobre cumprimento destas legislaçôes, nas empresas ou associaçóes que se submeteram a este processo.

Como delineamento para a elaboração do trabalho utilizou-se a pesquisa bibliográfica e documental. A parte inicial do trabalho foi composta pela pesquisa bibliográfica como fonte de informaçóes sobre ao assunto. Segundo Gil (2008), "esta é desenvolvida a partir de material já elaborado principalmente de livros e artigos científicos". O levantamento de dados foi realizado através de pesquisa documental, que de acordo com Gil (2008) se assemelha muito a pesquisa bibliográfica, porém a exploração dos dados consiste de fontes documentais que podem ser documentos de primeira ou segunda mão. Documentos de primeira mão são aqueles que não receberam nenhum tratamento analítico, tais como: documentos oficiais, reportagens de jornal, cartas, contratos, filmes, fotografias, entre outros. Já os documentos considerados de segunda máo são aqueles que, de alguma forma, foram analisados, tais como: relatórios de pesquisa, relatórios de empresas, tabelas estatísticas, entre outros.

O levantamento de dados foi realizado através de verificação de documentos de segunda mão, ou seja, através da verificação e análise dos relatórios (auditoria principal e monitoramentos) de certificação florestal das unidades de manejo de florestas nativas da região Amazônica certificadas 
no país no período de 1997 a 2007, pelo sistema FSC. Estes são documentos públicos e contêm uma descrição das açôes desenvolvidas na unidade de manejo para o atendimento a todos os princípios e critérios definidos no padrão.

Os relatórios foram obtidos junto às certificadoras credenciadas pelo FSC: Programa SMART WOOD - Representante no Brasil: IMAFLORA - Instituto de Manejo e Certificação Florestal e Agrícola (IMAFLORA, 2007); SCS - Scientific Certification System, Inc. - Programa Forest Conservation (SCS, 2007); SGS - Société Générale de Surveillance - Programa SGS (SGS, 2007). Não foi verificado nenhum relatório do sistema de certificação ABNT/CERFLOR, pois náo havia neste período nenhuma área certificada de florestas nativas, pelo mesmo, na Regiáo Amazônica.

A análise teve foco no Princípio 1, relacionado à "Obediência às leis e aos princípios e critérios do FSC". Porém, em cada relatório, buscou-se fazer o levantamento de todas as não-conformidades envolvidas no processo de certificação. Não-conformidade é o termo utilizado para indicar que na unidade de manejo florestal estáo sendo descumpridos alguns requisitos que são prescritos pelo padrão. Quando há um descumprimento destes é aplicada à unidade de manejo uma não-conformidade. A partir da identificação e análise destas não-conformidades foi possível desenvolver o estudo sobre as principais dificuldades destas empresas e associaçôes no cumprimento da legislação.

\section{RESULTADOS E DISCUSSÃO}

A primeira certificação de florestas nativas da região Amazônica ocorreu em 1997 e pertence a uma empresa que mantém o certificado até os dias atuais. Neste estudo foram verificados os relatórios das 27 Unidades de Manejo Florestal (UMF) certificadas na regiáo Amazônica até o ano de 2007, que representam uma área de mais de 2,9 milhôes de hectares (Tabela 1). Esta área é expressiva se comparada com a área total brasileira certificada, porém, esse valor representa apenas 0,58\% da área total da Floresta Amazônica (Tabela 2). O valor total da área da Floresta Amazônica (Tabela 2) é aproximado e corresponde a chamada Amazônia Legal, compreendendo os estados Amazonas, Amapá, Mato Grosso, oeste do Maranhão, Pará, Rondônia, Roraima e Tocantins.

Os totais de não-conformidades encontradas nestes relatórios são apresentados na Tabela 3 . Toda não-conformidade constatada é analisada e classificada quanto à sua gravidade. Uma não-conformidade é considerada maior se resultar em uma falha fundamental para atingir o objetivo do critério considerado. Várias não-conformidades menores (em um mesmo critério) poderão determinar uma não-conformidade maior (IMAFLORA, 2007).
Tabela 1 - Números totais das UMF certificadas pelo sistema FSC.

\begin{tabular}{lcc}
\hline & Unidades Certificadas & $\begin{array}{c}\text { Área certificada } \\
\text { (ha) }\end{array}$ \\
\hline No mundo & 987 & 120.016 .760 \\
No Brasil & 63 & 4.720 .645 \\
Região Amazônica & 27 & 2.918 .400 \\
\hline
\end{tabular}

Fonte: FSC (2010).

Tabela 2 - Comparação das UMF certificadas com a área total da Floresta Amazônica.

\begin{tabular}{lccc}
\hline & Área total (ha) & Área certificada (ha) & $\%$ \\
\hline Região Amazônica & 500.000 .000 & 2.918 .400 & 0,58 \\
\hline
\end{tabular}

Fonte: GTA (2010); FSC (2010).

Tabela 3 - Total de Não-Conformidades (NC) quantificadas nos relatórios de certificação da Região Amazônica.

\begin{tabular}{lccc}
\hline & Total de NC & $\%$ & $\begin{array}{c}\text { Média por } \\
\text { UMF }\end{array}$ \\
\hline $\begin{array}{l}\text { Todos os } \\
\text { Princípios }\end{array}$ & 1058 & 100 & 39,2 \\
Princípio 1 & 129 & 12,2 & 4,8 \\
\hline
\end{tabular}

$\mathrm{Na}$ Tabela 4 é apresentado o total de não-conformidades de acordo com sua gravidade. Destas 129 não-conformidades verificadas 36 foram do tipo maior, representando $23 \%$ das não-conformidades maiores totais, um valor alto para apenas um princípio, verificando que problemas referentes ao descumprimento das leis são freqüentes no Brasil. Após a análise das não-conformidades referentes ao princípio 1 , estas foram selecionadas e agrupadas em oito categorias (Figura 1). Pode-se perceber um grande número de não-conformidades referentes à legislação trabalhista e ambiental, constituindo-se os principais problemas das UMF de florestas nativas da região Amazônica no Princípio 1.

Problemas quanto à legislação trabalhista são freqüentes no Brasil, inclusive no setor florestal, que demanda grande quantidade de mão-de-obra. Segundo Cardoso \& Lage (2005), o sistema de regulação do trabalho de determinado país pode ser muito detalhado e rígido em termos formais, mas muito flexível na prática, simplesmente porque os empregadores podem escolher não cumprir o que a lei prescreve. E esse é o caso do Brasil. De acordo com Pires (2008), as empresas aqui no Brasil tem que cumprir 922 artigos do código trabalhista, 
Tabela 4 - Total de Não-Conformidades (NC) de acordo com a gravidade.

\begin{tabular}{lcccc}
\hline & NC Maior & $\%$ & NC Menor & $\%$ \\
\hline Todos os Princípios & 164 & 100 & 894 & 100 \\
\hline Princípio 1 & 36 & 23 & 93 & 10,4 \\
\hline
\end{tabular}

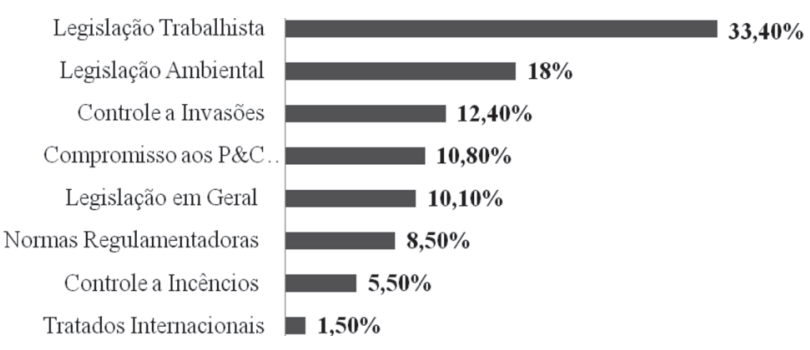

Figura 1 - Relação das não-conformidades do Princípio 1 separadas por categoria Compromisso aos P\&C do FSC(\%)

além de 46 artigos da Constituição Federal, 79 convençóes da Organização Internacional do Trabalho (OIT), 33 normas de saúde e segurança (que somam mais de 2 mil itens), e muitos outros atos administrativos e decisóes judiciais, que acrescentam valores altíssimos aos encargos trabalhistas. Com isso, cumprir ou não a legislação trabalhista passa a ser, do ponto de vista estrito da gestão de uma empresa, uma decisão racional de custo-benefício do empreendedor individual. Se o empregador considerar que os custos trabalhistas são muito altos, ele pode decidir correr o risco de não pagá-los (Cardoso $\&$ Lage, 2005).

Dos problemas referentes à legislação trabalhista $(33,4 \%)$ as principais questôes estavam relacionadas aos trabalhadores terceirizados (Figura 2). O principal problema foi a falta de regularização dos funcionários terceirizados $(41,9 \%)$, referentes aos pagamentos, contratos e à equipamento de segurança. As empresas maiores têm a tendência de contratar serviços terceirizados como forma de minimizar seus custos totais, uma prática comum não somente na área florestal. Porém, "a certificação FSC considera os trabalhadores terceirizados da mesma maneira que os trabalhadores próprios, isto é, eles devem ter os mesmos direitos e benefícios. Para a certificação, não é aceitável que a terceirização seja uma forma de flexibilização das relaçôes de trabalho e dos direitos dos trabalhadores. O FSC considera que os princípios e critérios de certificação se aplicam a todos os trabalhadores operando na UMF e prevê que as diferenças de tratamento entre trabalhadores próprios e terceirizados devem ser minimizadas" (IMAFLORA, 2006).

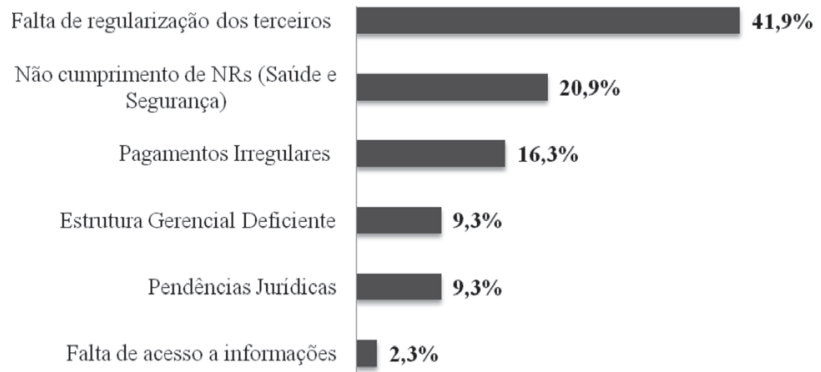

Figura 2 - Relação das não-conformidades referentes à Legislação Trabalhista (\%)

Desta forma, mesmo que as não-conformidades não foram de problemas diretos da empresa que se submeteu à certificaçáo, acaba se tornando parte de um todo de acordo com o padrão FSC. Normalmente as empresas terceirizadas são empresas menores, que atuam em apenas uma das atividades do manejo florestal, o que as torna menos visada para uma fiscalizaçáo trabalhista. Segundo Cardoso \& Lage (2005), se uma empresa possui 50 ou mais empregados e apresenta alguma ilegalidade as chances de ser autuada são muito altas.

$\mathrm{Na}$ Amazônia, uma das características do trabalho florestal é a concentração das atividades na época seca, em geral entre junho e dezembro. Normalmente, os trabalhadores são contratados durante esse período, muitas vezes sem registro em carteira, e quando termina a safra são dispensados. Como náo existem garantias de ter os mesmos trabalhadores no ano seguinte, as empresas também não investem em treinamento. Além disso, para evitar gastos com horas extras e garantir a produção necessária na época seca, as empresas pagam por produção e não formalizam os contratos de trabalho. Portanto, é comum que os trabalhadores florestais năo recebam uma série de direitos, como férias, $13^{\circ}$ salário e Fundo de Garantia, entre outros. Entretanto, para obter a certificação é obrigatório o cumprimento da legislação trabalhista e todo trabalhador envolvido na operação, seja direto ou de prestadores de serviços, deve ter registro em carteira (IMAFLORA, 2006). A cultura da região influencia no descumprimento das legislaçôes, porém para se receber a certificação do manejo florestal é necessária cumprir as leis. Por esta questấo todas as empresas e associaçóes se mostraram favoráveis a resolver as não- conformidades, regularizando seus trabalhadores, conforme foi verificado nos relatórios de monitoramento.

Os problemas referentes aos pagamentos irregulares como de horas extras, férias e encargos representaram 16,3\% do total. Normalmente, faltavam-se os documentos comprobatórios dos pagamentos. As questóes foram resolvidas e em alguns casos a empresa até mudou sua política de trabalho, estabelecendo assim um sistema de pagamento de horas extras e firmando acordos com os sindicatos. 
Em diversos casos, a certificação levou à estabilidade de emprego, fazendo com que o trabalhador não mais fosse demitido durante o período de entressafra. Algumas empresas certificadas estabeleceram, em conjunto com os sindicatos e o Ministério do Trabalho, um mecanismo chamado banco de horas. Durante o período de seca os trabalhadores operam uma hora a mais por dia. Estas horas são acumuladas e permitem a continuidade do contrato de trabalho nos meses que a operação florestal é paralisada devido às chuvas. Os trabalhadores têm a vantagem da segurança da renda ao longo de todo o ano e a estabilidade de emprego (IMAFLORA 2006).

Os problemas referentes à saúde e segurança do trabalhador foram apresentados através do item de não cumprimento das Normas Regulamentadoras (NRs) e representaram o segundo maior problema nas questóes trabalhistas (Figura 2). Estas questôes referentes à saúde e segurança do trabalhador são tratadas nas 33 NRs que têm por objetivo prevenir os acidentes e as doenças no local de trabalho, buscando identificar, controlar e até mesmo eliminar os riscos no ambiente de trabalho.

As empresas do setor florestal apresentam uma série de riscos que podem causar danos a segurança e saúde do trabalhador. Para que estes problemas não ocorram, uma série de requisitos devem ser seguidos náo somente pelo empregador, como também pelo empregado. Desta forma, o uso de EPI (Equipamento de Proteçấo Individual) é um dos quesitos fundamentais de segurança para o trabalhador e por isso é verificado em todas as auditorias nas diversas operações florestais. Este tipo de problema foi verificado no item de Não cumprimento das NRs. Encontraram-se duas não-conformidades pela falta de uso de EPI, indicando que o sistema de saúde e segurança do trabalho na empresa não estava funcionando adequadamente . As duas foram consideradas condiçôes graves, ou seja, "Maiores" e resolvidas imediatamente, por meio de aquisição de kits completos de EPI e sua devida utilização. Além disso, criou-se um sistema de monitoramento para garantir uso adequado e contínuo dos EPIs por todos os trabalhadores da UMF.

Para obter a certificaçấo todas as condiçôes de segurança do trabalhador devem ser mantidas, assim, pode-se dizer que a certificação florestal vem contribuindo para aumentar a segurança dos trabalhadores em campo e diminuir os acidentes de trabalho.

As questôes referentes à Legislação Ambiental foi o segundo item com maior número de incidências, constituindo 18\% do total (Figura 1). Destas, as duas maiores ocorrências foram problemas relacionados à falta de autorizaçôes e documentos exigidos pelos órgãos ambientais competentes e às Áreas de Preservação Permanente (APPs) (Figura 3).

Náo foi relatado nenhum problema relacionado à área de reserva legal nos relatórios de florestas nativas analisados.

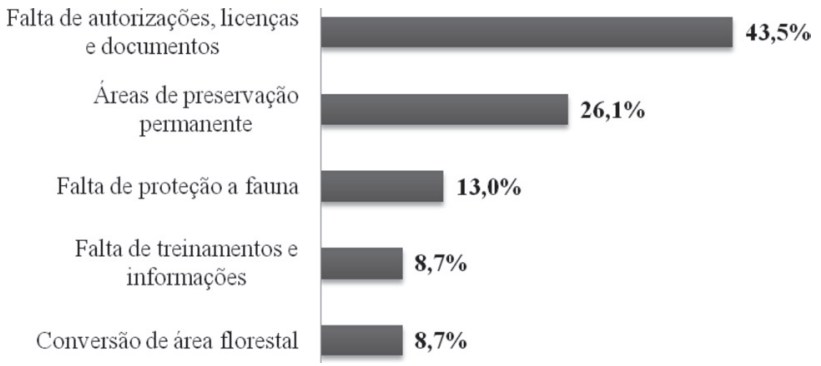

Figura 3 - Relação das não-conformidades referentes à Legislação Ambiental (\%).

Este fato pode ser explicado pela prática do manejo florestal ocorrer em toda a propriedade, excetuando as APPs. Neste caso, a atividade principal do proprietário é o manejo florestal e, mesmo podendo converter os $20 \%$ da terra para outros usos, na maioria das vezes ele não faz, atendendo, conseqüentemente os $80 \%$ de Reservas Legal exigidos para as áreas com floresta na regiáo.

Quando se diz respeito à certificaçáo de florestas nativas, há o envolvimento de certificaçōes empresariais e comunitárias, e do total destas não-conformidades referentes a legislação ambiental, cerca de $70 \%$ estavam nos relatórios das certificaçôes empresarias e o restante nos relatórios de certificação comunitária, evidenciando um maior comprometimento destas com relação às questôes ambientais (Tabela 5). Ressalta-se, também, que a maioria das certificaçôes comunitárias é referente ao manejo de Produtos Florestais Não Madeireiros (PFNM), o que, pela sua essência, interfere menos nos recursos naturais.

Tabela 5 - Quantificação (\%) das não-conformidades por tipo de certificação.

\begin{tabular}{lccc}
\hline Não-conformidade & Empresarial & Comunitária & Total (\%) \\
\hline $\begin{array}{l}\text { Autorizações, licenças e } \\
\text { documentos }\end{array}$ & 21,75 & 21,75 & 43,5 \\
Questões referentes à APP & 26,1 & 0 & 26,1 \\
Proteção à fauna & 8,65 & 4,35 & 13 \\
Conversão de parte da floresta & 8,7 & 0 & 8,7 \\
$\begin{array}{l}\text { Falta de treinamentos e } \\
\text { informações }\end{array}$ & 4,35 & 4,35 & 8,7 \\
\hline Total (\%) & 69,55 & 30,45 & 100 \\
\hline
\end{tabular}

Quanto às não-conformidades relacionadas às APPs, foram todas evidenciadas nos relatórios empresariais, percebendo-se assim uma maior dificuldade das empresas em cumprirem totalmente a legislação ambiental. Das não-conformidades referentes às APPs os problemas foram variados. Houve duas $(8,7 \%)$ náo-conformidades consideradas graves ou "Maiores". Ambas foram solucionadas rapidamente, pois o prazo para execução, nestes casos, é de no máximo três meses. 
As outras não-conformidades menores foram referentes ao mapeamento, recuperação e manutenção das áreas de APP, garantindo que năo haja desbastes, nem exploraçóes indevidas. As APPs têm como função a manutenção da qualidade do solo, das águas e também para funcionar como corredor ecológico para a fauna, deste modo se torna justificável sua recuperação e conservação e deve ser avaliada com bastante atenção nas auditorias de certificação.

A exigência de proteção e recuperação das APPS no processo de certificação está contribuindo de forma complementar à lei e eficientemente com os conceitos de conservaçáo da natureza. O náo táo "novo" Código Florestal brasileiro foi editado há 38 anos; seu anteprojeto foi proposto há 53 anos. $\mathrm{Na}$ atualidade, muitos sabem de sua existência, alguns lhe conhecem (parcialmente) o conteúdo; mas poucos proprietários (de terras), em pleno século XXI, aceitam-no como instrumento válido e legítimo para a proteção do patrimônio florestal brasileiro (Ahrens, 2003). O item de maior porcentagem referente à legislação ambiental (Figura 3) foi relacionado à falta de documentos, autorizaçôes e licenças dos relatórios de certificação de florestas nativas na região amazônica e estas foram encontradas tanto em relatórios de certificação comunitária quanto em certificaçáo empresarial. Neste item, apresentouse o maior número de não-conformidades graves ou "Maiores". Destas, três se tratavam da ATPF (Autorização de Transporte de Produtos Florestais) emitida pelos órgãos ambientais. Esta autorização é suma importância para se provar que o produto transportado não vem de exploração ilegal, por isso, foi considerado como um problema grave. Segundo um estudo realizado no Pará em 2005, “o transporte de madeira sem as Autorizaçôes de Transporte de Produtos Florestais (ATPF) foi a infração mais freqüente e o armazenamento de madeira sem autorização a segunda infração mais cometida nos processo verificados" (Brito \& Barreto, 2005). Porém, segundo o mesmo estudo, essa predominância de casos relacionados ao transporte e armazenamento de madeira sem autorização parece refletir a maior atuação da fiscalização nas vias de transporte e nas empresas madeireiras em vez de no interior da floresta onde o desmatamento e exploraçấo ilegal ocorrem (Brito \& Barreto, 2005).

A partir dos dados obtidos pode-se verificar que apesar de necessários e obrigatórios todos os documentos, autorizaçôes e licenças, havia problemas nas áreas de manejo analisadas e, após a certificação florestal, os casos foram solucionados comprovando assim a contribuiçáo benéfica do processo.

\section{CONCLUSÕES}

Todas as unidades de manejo de florestas nativas na regiáo Amazônica apresentaram não-conformidades em relação ao cumprimento da legislação, com apenas uma exceção, indicando que há dificuldades para adequação legal no país.

O cumprimento da legislação trabalhista e ambiental são os principais problemas enfrentados em relação à questáo jurídica pelo manejo de florestas nativas.

A adequação das Áreas de Preservação Permanente e regularizaçáo de documentos, bem como autorizaçôes de órgãos ambientais, são os principais problemas ambientais para a certificaçấo de florestas naturais na regiáo amazônica.

A certificaçáo florestal induz beneficamente as empresas e associaçóes a cumprirem as legislaçóes pertinentes às suas atividades, fazendo com que sejam assumidas suas responsabilidades legais.

A certificação florestal é um mecanismo que efetivamente influencia o cumprimento da legislação do país, devendo assim, ser incentivada por toda a sociedade, seja por meio da preferência dos consumidores por produtos certificados ou por meio de incentivos governamentais e não governamentais à sua implementação pelas organizaçôes do setor florestal brasileiro.

\section{AGRADECIMENTOS}

Ao CNPq (Conselho Nacional de Desenvolvimento Científico e Tecnólogico) pela concessão da bolsa para realização desta pesquisa.

\section{BIBLIOGRAFIA CITADA}

Alves, R. R.; Jacovine, L. A. G.; Einloft, R. 2009. Forest certification in the Amazonia region. Revista Madeira, 120: 62-65 (in Portuguese).

Ahrens, S. 2003. The "New" Brazilian Forest Code: Basic Juridical Concepts. Congresso Florestal Brasileiro, 8. Anais; 14 pp (in Portuguese, with abstract in English).

Brito, B.; Barreto, P. 2005. Application of the law of Environmental Crimes by the Federal Court in the Forest Sector of Pará. Revista de Direito Ambiental, 37 (in Portuguese).

Cardoso, A.; Lage, T. 2005. The labor inspection in Brazil. Revista de Ciências Sociais, 48 (3): 451-490 (in Portuguese).

Clement, C. R.; Higuchi, N. 2006. The Amazonia forest and Brazil's future. Revista Ciência e Cultural, 58(3): 44-49 (in Portuguese).

FRA. 2005. Food and Agriculture Organization (http://www.fao. org/forestry/fra/fra2005). Acesso: 05/01/2010.

FSC - Forest Stewardship Council. 2010. Global FSC certificates: type and Distribution, January 2010. (http://www.fsc.org/fileadmin/ web-data/public/document_center/powerpoints_graphs/ facts_figures/Global-FSC Certificates-2010-01-15-EN.pdf). Acesso em: 15/02/2010. 
Gil, A. C. 2008. Methods and Techniques of Social Research. 6a edição, São Paulo, SP, Brasil. 200 pp.

GTA (Work group of amazonia). 2010. The brazilian amazonia. (http://www.gta.org.br/amazonia.php). Acesso em 15/01/2010.

IMAFLORA (Institute of Management and Forest and Agricultural Certification). 2007. (www.imaflora.org). Acesso em: 08/09/07.

IMAFLORA. 2006. Brazil certificate - the history of forest certification in Brazil. $2^{\text {a }}$ edição. Piracicaba, SP, Brasil. 128 pp (in Portuguese).

IMAFLORA, 2007. Guidelines for the Evaluation of Forest Management. (www.imaflora.org). Acesso: 08/09/07.

INMETRO (National Institute of Metrology, Standardization and Industrial Quality). ABNT/CERFLOR. Certified companies. (http://www.inmetro.gov.br/qualidade/cerflor_empresas.asp). Acesso em 15/01/2010.

Nardelli, A.M.B.; Griffith, J.J. 2003. Theoretical Model For Understanding Corporate Environmentalism In The Brazilian
Forestry Sector. Revista Árvore, 27(6): 855-869 (in Portuguese, with abstract in English).

Pires, R. 2008. Compatibilizing social rights with competitiveness: inspectors of labor and the implementation of the labor legislation in Brazil. Texto para Discussão (IPEA), v.1354, 41 pp. (in Portuguese, with abstract in English)

SCS - Scientific Certification System, Inc. - Programa Forest Conservation. 2007. (www.scscertified.com/forestry/forest_ certclients). Acesso em: 07/09/07.

SGS - Société Générale de Surveillance. 2007. Programa SGS. (www. forestry.sgs.com/forestry_services_index_v2/mini_site_forestry_ certification/forest_management_reports/qualifor_fmr_brazil. htm). Acesso em: 12/09/07.

Recebido em 24/03/2010

Aceito em 19/05/2010 
